Kansas State University Libraries

New Prairie Press

\title{
ON-FARM RESEARCH IN A DECENTRALIZED INFORMATION MODEL OR GRASSROOTS STATISTICS
}

Derrick N. Exner

Jennifer Kendall

Dick Thompson

Follow this and additional works at: https://newprairiepress.org/agstatconference

Part of the Agriculture Commons, and the Applied Statistics Commons

\section{(c) (1) $\Theta(9$}

This work is licensed under a Creative Commons Attribution-Noncommercial-No Derivative Works 4.0 License.

\section{Recommended Citation}

Exner, Derrick N.; Kendall, Jennifer; and Thompson, Dick (1998). "ON-FARM RESEARCH IN A DECENTRALIZED INFORMATION MODEL OR GRASSROOTS STATISTICS," Conference on Applied Statistics in Agriculture. https://doi.org/10.4148/2475-7772.1284

This is brought to you for free and open access by the Conferences at New Prairie Press. It has been accepted for inclusion in Conference on Applied Statistics in Agriculture by an authorized administrator of New Prairie Press. For more information, please contact cads@k-state.edu. 


\title{
ON-FARM RESEARCH IN A DECENTRALIZED INFORMATION MODEL OR GRASSROOTS STATISTICS
}

\author{
Derrick N. Exner \\ PEI On-Farm Research Coordinator, 2104 Agronomy Hall, ISU, Ames \\ IA 50011 \\ Jennifer Kendall \\ Not Fade Away Farm, 1275 Hogback Bridge Road, Earlham, IA 50072 \\ Dick Thompson \\ Practical Farmers of Iowa, $2035190^{\text {th }}$ St. Boone, IA 50036
}

\begin{abstract}
Practical Earmers of Iowa (PEI) is an organization that seeks to provide interactive methods of relaying information through farmer-to-farmer sharing (farm field days, workshop discussions, networking) and the generation of new information. On-farm research (OFR) is an important information-generating activity of this group. PFI has shown that key to doing research on farms lies in combining practical protocols with the statistician's old familiar friends - replication and randomization.

We provide background on PFI and how PFI cooperators came to using strip plots and paired comparisons to answer fundamental questions about what to do on their individual farms. We discuss the challenges faced by OER cooperators, how those challenges are met and how the simple paired comparison t-test works for the OFR cooperator to answer that very typical experimental question posed by producers: "Is alternative practice 'b' better than, worse than, or no different from my current practice 'a'?"

Keywords: sustainable farming, on-farm research, t-test
\end{abstract}




\section{Introduction}

In the United States, landmark $19^{\text {th }}$ and early $20^{\text {th }}$ Century legislation establishing the Land Grant colleges and the Extension service has set the tone for agricultural research and established a model for the relationship of science to farming that is still in place. Traditionally, in the U.S., universities have been responsible for applying science to agriculture, and the role of the Extension service has been to disseminate these applications in the farming community.

A continuing discussion concerns whether this is a "top-down" model. It has elements of a centralized information structure, but mitigating factors have also softened possible negative consequences. For example, most scientists and administrators traditionally came from farming backgrounds themselves and so carried a sense of agriculture's needs and the appropriate use of science on the farm. Moreover, field personnel in an organization like the Extension Service hear from their clients, both individually and through county Extension councils. Farm organizations too make their needs known to the Land Grants, although those recommendations generally speak more to content than to the form of information transfer.

\section{Farm Research Information Delivery}

Whatever the merits of the traditional system, changing circumstances are giving rise to new kinds of research and extension programs and a new relationship with farming clients. The Extension Service was once the only widely available source of scientific agricultural information. In Iowa, before reliable roads, train cars were used as classrooms traveling from one community to another, bringing the news of good farming practices. The standard information delivery style was the lecture.

Lectures are still the preferred information transfer mode for much technical material, but farmers can now choose from dozens of information providers. In fact, in the "Information Age," the 
farmer's challenge is not so much obtaining information, as discriminating among data from multiple sources and applying that information to an environment that is unique - the particular farm of that producer. Not only is the combination of soils, climate, equipment, and operator preferences unique to the farm, but each operation's complement of enterprises and its accommodation with its surrounds - the farming system - is distinctive.

As such, "packaged answers," whether from industry or university research, have their limitations. Farmers need interactive means of information acquisition and validation, ones that they can tailor and apply to their own circumstances. They need to "kick the tires" on the technical offerings form university and industry, and they want to resize and recombine technologies to fit their situations.

\section{Practical Farmers of Iowa (PFI)}

PEI is an organization that seeks to provide such vehicles through farmer-to-farmer information sharing (farm field days, workshop discussions, networking) and the generation of new information. On-farm research (OFR) is an important informationgenerating activity of this group.

On-farm research fits well with the general philosophy of the organization, which is sympathetic to what has become known as sustainable agriculture. Sustainable agriculture has had myriad definitions but in general is consistent with optimization of onfarm resources (biological, management, system synergies) and cautious use of off-farm resources (production inputs, lending capital, gee-whiz technology) in order to optimize the longevity of the farming operation within a stable natural environment. Sustainable farmers face the same information pressures faced by any farmer with an additional twist. Until the last decade, the university system didn't offer information applicable to their individual situations. In the absence of support from the Land Grant institutions, a degree of mistrust built up in parts of the 
sustainable agriculture community - a further impetus for these farmers to carry out their own research.

\section{The PFI Approach to OFR}

Notwithstanding the populist rhetoric, just how does one go about doing his or her own agricultural research? After a decade of effort, PFI has shown that the challenges to doing research on farms are formidable but by no means insurmountable. The key lies in combining practical protocols with the statistician's old familiar friends - replication and randomization.

Farmer-conducted research has always emphasized practicality; after all, producers have to wrest a living from the land at the same time as they seek answers to their inquiries. However, onfarm research, in its departure from the garden plot-sized experimental units seen on experiment stations, often strays into perilous territory. All too often, one sees a practice at the top of a hill compared to another at the bottom of the hill. Consider that the farmer carrying out this demonstration may have had in mind a very clear baseline of how crops perform at the top and the bottom of that hill. Unfortunately, no one else viewing the trial is in a position to make such allowances, and the reputation of on-farm research suffers accordingly.

Sometimes distinctions are drawn between experiments and demonstrations, which are intended to illustrate what is already known. As information providers, we have contributed to the poor image of OFR by occasionally conducting field demonstrations with insufficient replication to prove our point. If the trial results are not what we expect, we dismiss them as statistical aberrations, yet our target audiences tend to believe their eyes before our explanations. Experience shows that the most effective demonstration is an adequately replicated trial.

The same tension is present with on-farm research that involves many farms but includes few replications at any one site. From the research standpoint, this approach may be preferable, since it can evaluate treatment effects across a variety of 
environments. However, the audience at an individual farm may, based on their single observation, reach conclusions opposite from those of the principal investigators. With these trials special efforts are necessary to convey "the big picture" to the target audience.

Practical Farmers of Iowa has used OFR first as a self-help tool that individual producers can use to derive answers that may be sensitive to the unique combination of soils, equipment, management style, and history that characterizes each farm. This carries both limitations and advantages. The chief advantages are flexibility and relevance. Farmers are answering their own most pressing questions, and so they are quite committed to the research. Their enthusiasm can be contagious, and it has not been unusual for half a dozen or more producers to be researching the same topic simultaneously. For example, in the early 1990s, a cropping system called strip intercropping was such a topic of shared research interest; in the mid-1990's it was fertilizer placement; in the late 1980's tillage systems were the basis of many trials; in the mid-1980's the "hot" topic was nitrogen rates for corn.

The contagion of research topics with this approach to OFR is fortunate, because it tends to offset one of the drawbacks, i.e. the limitation of research that is conducted at a single siteyear only. Results from such a trial are difficult to generalize beyond the year and field in which the trial took place. PFI farmer researchers who carry out one-of-a-kind trials customarily repeat the experiment at least once, and they caution other producers that a single year's results must be taken with caution. In the case of multiple-site trials, because of the decentralized nature of the research network and the uniqueness of each farm's management, it is sometimes difficult to ascribe location $x$ treatment interactions clearly to location or to treatment differences.

\section{User-Friendly Protocols}


Consistent with the view of OFR as a self-help tool, PFI often makes use of a "recipe" developed by farmers and agronomists in the mid-1980s. Boone county producer Richard Thompson had begun attempts at on-farm research several years before then, "blowing up" the "garden plot" layout typical of experiment station research to fill an 80-acre field. He discovered that with such huge experimental units, trial results reflected field variability more than treatment effect.

A similar lesson about field variability comes from University of Nebraska agronomist Charles Erancis, who shows farmer audiences a field layout of a corn hybrid experiment with ten experimental units and ten yields ranging widely. Francis asks the question, "Which hybrid would you choose?" After a suitable pause, he explains that every yield was from the same hybrid. Farmers relate to the explanation that fence lines, sandy spots, wet areas, etc., alter the uniformity of almost every field to some degree. They further accept that there will always be unidentified sources of variation, despite our best efforts to explain crop response. This discussion lead easily to the importance of replication and of appropriately sized experimental units.

It was also University of Nebraska agronomist Charles Francis who suggested the paired comparison design. Limiting the number of treatments to two reduced the physical distance - and consequently the field variability - between plots. It also simplified the arithmetic required for a t test, since only a single sum of squares need be calculated. A producer can thus conceptualize an experiment, carry it out, and analyze the results independently. Consultants and extensionists can provide needed assistance as facilitators (rather than as directors of the process), since farmers may need help interpreting experimental results and understanding the meaning of statistical significance and confidence intervals.

The paired-comparison also corresponds well to a very typical experimental question posed by producers: "Is alternative practice ' $b$ ' better than, worse than, or no different from my 
current practice ' $a$ '?" A two-tailed t test of a paired comparison trial addresses this experimental question well. The temptation is always present to add more treatments, and sometimes a third treatment is required as a check, or control, but this increases the experimental error caused by field variability. This is especially true if treatments are added at the expense of replications due to land limitations. PFI trials typically call for six reps. If additional treatments are included, additional replication is desirable.

Another factor limiting the number of treatments is that very little farmer research attempts to develop a response curve. The producer may compare, for example, two sources of crop nutrients, each applied at a rate determined from availability formulas provided by agricultural scientists. The producer will typically measure plant tissue and crop yield to compare those fertility sources in the manner used. Farmer researchers generally see themselves showing whether it works; they see the scientist's role as showing how to apply.

The other innovation away from the "garden plot" experimental layout was the use by farmers of experimental units that are narrow (the width of one or two passes of the field equipment) and long (the length of the field). The narrowness of these strips helps reduce field variability from one to the next, but the strips are wide enough that the experiment can be "farmed" practically. The assumption is made that field variability along the length of strips will be similar among strips within a replication and will affect all treatments similarly. Each strip is harvested separately using the standard farm equipment, and yields are measured by means of a scale or weigh wagon.

PEI on-farm trials have included factorial experiments and split plot designs, as well as some livestock and cropping system trials that are difficult to replicate. However, the most common form of OFR implemented is still the paired-comparison in six replications, with long, narrow strips for experimental units. Rzewnicki et al. (1988) compared PFI paired-comparison trials conducted in 1987 with field-scale trials with or without 
irrigation conducted on experiment stations. The authors used as one indicator of statistical precision the coefficient of variation (CV) of a trial. They reported that Nebraska experiment station CVs for yield of irrigated corn were in the range of $8 \%$ to $15 \%$, while CVs for yield of irrigated soybeans were $6 \%$ to $12 \%$. Compared to this were 23 PFI trials with an average $\mathrm{CV}$ of $2.7 \%$ and a range of $0.7 \%$ to $5.9 \%$. Given these CVs and the number of replications, the researchers concluded that the PEI trials had a 79\% to 99\% probability of detecting yield differences of $10 \%$.

The use of long, narrow harvest strips is a departure from much agricultural plot work. Shapiro et al. (1989) compared nitrogen response yield data from machine combined corn strips and hand harvested subplots of 12.2 row-meters in length on 10 irrigated and 4 dryland site-years. Machine harvested strips had a lower error sum of squares than hand harvested plots in all but one trial. These researchers concluded that the harvest of long, narrow strips increased statistical precision over hand harvest of subplots by better representing the population of inference.

Parenthetically, it is worth noting that on-farm research can be not only accessible and reliable but economical. Considering that participating farmers provide gratis or at cost equipment, land, and management, experiment station research is dear by comparison. Eranzluebbers et al. (1988) surveyed trials on experiment stations and farms. Of the 19 experiment station trials examined, the average cost was $\$ 11,263$. Ninety-eight trials conducted on farms by scientists averaged $\$ 2,950$ each. Onfarm research conducted at 66 sites by 52 farmers averaged $\$ 800$.

\section{Farmer-Researcher Profiles}

To illustrate the role on-farm research can play in the evolution of a farming system, it may be useful to consider four producers who have carried out their own replicated research. These individuals have conducted research in cooperation with PFI for nearly a decade, during which time their interests and emphases have changed, thanks in part to on-farm research. 
1) Ron and Maria Rosmann operate a crop and livestock farm in the rolling hills of western Iowa. Like many members of PFI they are interested in limiting off-farm purchased inputs and optimizing resources internal to the farm. Their on-farm research, conducted over a decade, has focused largely on weed management and soil fertility issues. Weed management trials have compared ridge tillage to "conventional" tillage, herbicides to nonchemical control, different planting dates and populations, and forms of mechanical weed control using the rotary hoe and row crop cultivator. Ron has carried out fertility investigations to evaluate the efficacy of farm-generated manure or compost compared to synthetic fertilizer or purchased poultry manure. These step-by-step trials have given the Rosmanns the confidence to move their farm into organic certification.

2) Paul and Karen Mugge farm near Sutherland, in northwest Iowa. Many of Paul's research trials have focused on weed management or soil fertility. The weed trials have convinced him that he can use ridge tillage to successfully eliminate herbicides. Rather than use this approach on the entire farm, Mugge prefers to devote the necessary attention to a single field of herbicidefree soybeans, which he selis for a healthy premium. Many of his fertility trials have evaluated rates of nitrogen and/or livestock manure in different combinations. One outcome has been his use of deep placement of potassium and phosphorus fertilizers, a practice that has sometimes shown him significant yield benefits.

3) Tom and Irene Erantzen farm near Alta Vista, in northeast Iowa. "On-farm research is a flexible tool," says Tom. Some things you learn are useful in the short term, some in the long term, and some things you can't use at all." Tom considers his evaluation of the late spring soil nitrate test for corn a shortterm payoff, since it has helped him reduce $\mathrm{N}$ rates without yield reductions. Long term, his trials and those of other PFI research cooperators have convinced him that he can raise crops without herbicides, an important precondition to the family's decision to eventually farm organically. "The jury is still out" on grain amaranth, which he found he can grow but can't sell, and 
on hazelnuts. Tom and a neighbor conducted identical factorial trials of hazelnut establishment methods; on the neighbor's farm every treatment was successful, while Tom suffered considerable winterkill with every treatment. Frantzen says his on-farm research helps him write his five-year business plan by giving him reliable information on which to base decisions.

4) Richard and Sharon Thompson farm near Boone, in central Iowa, and many of the PEI research protocols were originally developed on the Thompson farm. Richard Thompson also credits the late spring soil nitrate test for corn; research with the test showed him that he needs no additional nitrogen beyond that from the green manure, livestock manure, and municipal sludge with which the soil is amended. With/without herbicide comparisons over five years showed that grassy weeds help suppress broadleafed weeds, and this is one reason Thompson uses cover crops. In this system, where the ground is untilled before planting, weed pressure is naturally suppressed; however, the cover crops and lack of tillage slow release of nitrogen to the crop. Further trials showed this "ridge-tillage" system was contributing to potassium deficiencies that additional fertilizer only partially reversed. In fact Thompson's potassium dilemma was the subject of a decision-case study developed at the University of Minnesota. The solution for Richard Thompson - and one developed largely through observation rather than replicated comparisons has been to use a moldboard plow to invert the upper six inches of soil once in every five-year crop rotation.

\section{Summary}

PEI continues its dedication to performing on-farm research and cooperating with research organizations along with cooperators of PFI. Each year two-to-three dozen PFI farmers function as research cooperators, and other members conduct informal trials. Most have not had as much experience with on-farm research as the farm families profiled, but they uniformly have questions they would like to answer through trials. They continue to seek answers through on-farm research and to find ways to answer their unique challenges. Not all experimental questions are amenable 


\section{Applied Statistics in Agriculture}

to the simple protocol described here, but simplicity is usually the best starting place in on-farm research design.

\section{References}

Franzluebbers, A., C.A. Erancis, P.E. Rzewnicki, R. Thompson, G.Lesoing, and R. Elmore. 1988. Relative costs and efficiencies of on-farm versus on-station research. p. 126. In Agronomy abstracts. ASA, Madison, WI.

Rzewnicki, P.E., R. Thompson, G.W. Lesoing, R.W. Elmore, C.A. Francis, A.M. Parkhurst, and R.S. Moomaw. 1988. On-farm experiment designs and implications for locating research sites. Am. J. of Alternative Agric. 3(4):168-173.

Shapiro, C.A., W.L. Kranz, and A.M. Parkhurst. 1989. Comparison of harvest techniques for corn field demonstrations. Am. J. of Alternative Agric. 4(2):59-64. 